\title{
Membranoproliferative glomerulonephritis associated with hyperthyroid phase of autoimmune thyroiditis
}

\author{
Gayani G G A ${ }^{1}$, Ediriweera H M A ${ }^{1}$, Heiyanthuduwa $\mathbf{S}^{2}$, Perera A $^{3}$, Dissanayake A $^{4}$, Weerarathne $\mathbf{T} \mathbf{P}^{5}$
}

Journal of the Ceylon College of Physicians, 2016, 47, 44-45

\begin{abstract}
Several cases of glomerulonephritis have been associated with autoimmune thyroid diseases. Most frequent renal lesion described was membranous glomerulonephritis presenting with nephrotic syndrome. This is a case history of a 58-year-old male presenting with nephrotic syndrome secondary to membranoproliferative glomerulonephritis and associated autoimmune thyroiditis. Hisserum complement levels were decreased with high titres of circulating antithyroid peroxidase antibodies and thyrotropin receptor antibodies. Renal biopsy showed membranoproliferative glomerulonephritis with the finding of increased tuft cellularity, lobular accentuation, neutrophilinfiltratedglomeruli and thickened basement membrane. Antithyroid drugs along with steroids led to significant reduction in proteinuria and resolution of oedema.
\end{abstract}

Key words: membranoproliferative glomerulonephritis, autoimmune thyroiditis

\section{Introduction}

Autoimmune thyroiditis and many primary glomerular diseases arise from the abnormalities of immunoregulation. The association of Graves' disease and autoimmune thyroiditis with other autoimmune diseases such as systemic lupus erythematosis, myas-

\footnotetext{
${ }^{1}$ Registrar in Medicine, University Medical Unit, Teaching Hospital Karapitiya, Galle, Sri Lanka

${ }^{2}$ Consultant Nephrologist, Teaching Hospital Karapitiya, Galle, Sri Lanka.

${ }^{3}$ Consultant Histopathologist, Teaching Hospital Karapitiya, Galle, Sri Lanka.

${ }^{4}$ Consultant Physician, Senior Lecturer in Medicine, Department of Medicine, Faculty of Medicine, University of Ruhuna, Galle, Sri Lanka.

${ }^{5}$ Professor in Medicine,Department of Medicine, Faculty of Medicine, University of Ruhuna, Galle, Sri

Corresponding author: GGGA,

E-mail: aysh2002@gmail.com
}

thenia gravis and autoimmune adrenal insufficiency is well known. But very few published data are available on the association of autoimmune thyroid disease with primary renal disease. Most reports have documented the association of autoimmune thyroiditis with membranous glomerulonephritis while membranoproliferative glomerulonephritis (MPGN) is a rare association of autoimmune thyroiditis. ${ }^{1}$

\section{Case report}

A 58-year-old previously healthy male presented with recent onset frothy urine, bilateral ankle oedema and difficulty in breathing. Over a period of one year, he had loss of weight of $8 \mathrm{~kg}$, increased appetite, sweating and palpitations which had not been investigated. He denied any painful neck swelling or eye symptoms.

On physical examination he had a body mass index of $18.8 \mathrm{Kg} / \mathrm{m}^{2}$, a regular heart rate of $120 \mathrm{bpm}$ and blood pressure of $170 / 100 \mathrm{mmHg}$, bilateral pleural effusions and bilateral ankle oedema. Small diffuse non tender enlarged thyroid gland was palpable. But there were features of thyroid eye disease. Optic fundi revealed Grade 2 hypertensive retinopathy.

The full blood count showed normochromic normocytic anaemia with a haemoglobin of $8.7 \mathrm{~g} / \mathrm{dl}$. Erythrocyte sedimentation rate, C-reactive protein, serum electrolytes and serum creatinine were within the normal range. His urine analysis showed microscopic haematuria (fieldfull red cells and 20-30 pus cells per high power field) with heavy proteinuria. His urine albumin to creatinine ratio was $1389 \mathrm{mg} / \mathrm{g}$ creatinine, serum albumin $28 \mathrm{~g} / \mathrm{l}$ and serum cholesterol was $380 \mathrm{mg} / \mathrm{dl}$. Other liver functions were within normal limits. His TSH was $<0.01 \mu \mathrm{lU} / \mathrm{mL}, \mathrm{FT}_{4}-2.86$ $\mathrm{ng} / \mathrm{L}(0.9-1.7)$ and $\mathrm{FT}_{3}-5.94 \mathrm{pg} / \mathrm{mL}(2-4.4)$. Chest radiograph showed bilateral moderate pleural effusions. Ultrasound scan of the abdomen was normal without sonographic evidence of renal parenchymal disease. Thyroid scan showed a diffuse goitre. Echocardiogram was normal. Hepatitis B \& C, rheumatoid factor, antinuclear antibody, double stranded DNA, anti neutrophil cytoplasmic antibody were negative, low C3 $(38 \mathrm{mg} / \mathrm{dl})$ with normal C4 were seen. anti-thyroid peroxidase antibodies (anti-TPO antibodies) were strongly positive $>140 \mathrm{U} / \mathrm{ml}(<35)$, with positive thyrotropin receptor antibodies (TRAb) $4.9 \mathrm{IU} / \mathrm{I}(<0.3)$. 
Renal biopsy showed increased tuft cellularity with lobular accentuation. Haematoxylin and eosin stain and periodic acid shift stain showed the glomeruli infiltrated by neutrophils and thickened basement membrane (Figure 1, 2). Red cell casts were seen within the renal tubules.

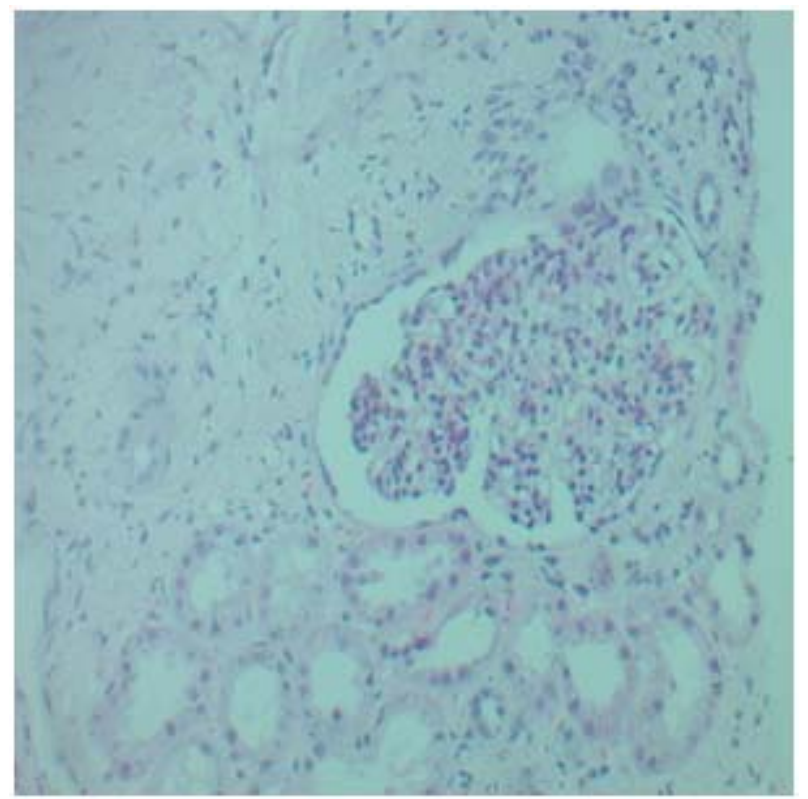

Figure 1. (Haematoxylin and eosin stain).

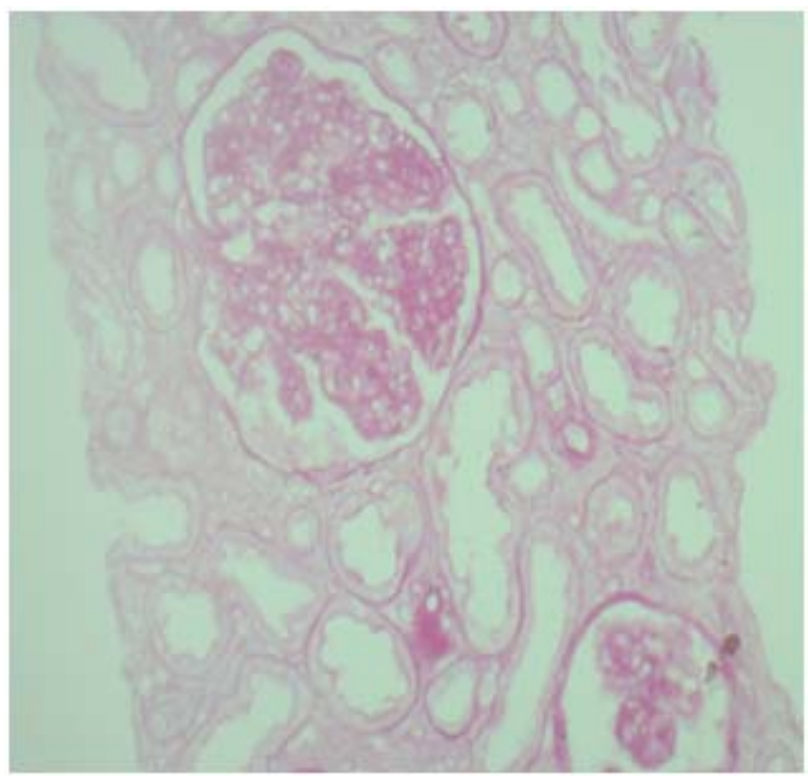

Figure 2. (Periodic acid schiff stain).

He was treated with carbimazole, propranolol and oral prednisolone $1 \mathrm{mg} / \mathrm{kg} / \mathrm{d}$, angiotensin receptor blocker and alendronate. His general condition markedly improved over one month with treatment and steroid dose had been tailed off gradually.

\section{Discussion}

Autoimmune thyroiditis is associated with glomerulonephritis. It has been reported that autoimmune thyroiditis is associated with mixed pathological morphology marked by predominant membranous glomerulopathy. But minimal change and membranoproliferative types also have been described..$^{1,2}$

Thyroid disease may be linked to different forms of glomerulonephritis. Both hypothyroidism and hyperthyroidism can be associated with different forms of glomerular disease. The most frequent association is with membranous glomerulopathy. Thyroid dysfunction has been reported to be associated with IgA nephropathy, mesangiocapillary or membranoproliferative glomerulonephritis and minimal change glomerulonephritis. Several mechanisms have been postulated to explain these associations. ${ }^{3}$

Anti-TPO antibody is a membrane associated haemoglycoprotein expressed only in thyrocytes and is one of the most important of thyroid gland antigens. It activates complement and is thought to be significantly involved in thyroid dysfunction and the pathogenesis of hypothyroidism later. Anti-TPO antibody measurement is the most sensitive test for detecting autoimmune thyroid disease where $90 \%$ positive in Hashimoto's thyroiditis and $60-80 \%$ in the course of Graves disease. TRAb is elevated in $80-90 \%$ of Graves disease and $15 \%$ of Hashimoto's thyroiditis. Immune complex deposits in the basement membrane of thyroid follicular epithelium and the glomeruli have been reported in patients with Hashimoto's thyroiditis and membranous and membranoproliferative glomerulonephritis. ${ }^{4,5}$ Thyroxin replacement therapy along with steroids lead to significant decrease in proteinuria and resolution of oedema.

In conclusion, we recommend that evaluation of thyroid status would be beneficial in patients with membranoproliferative glomerulonephritis, where an autoimmune origin is suspected or established.

\section{References}

1. Valentine M, Bueno B, Gutiérrez E, MartnezA, Gonzalez E, Espego B, Torres A. Membranoproliferative glomerulonephritis associated with autoimmune thyroiditis. Nefrologia 2004; 3: 43-8.

2. Saba A, Bagri N, Mehera N, Dubey NK, Batra V, Membranoproliferative Glomerulonephritis associated with autoimmune thyroditis. J. Paediatric Endocrinology and Metabolism 2011; 24 (9-10): 789-92.

3. Iglesias P, Diez JJ. Thyroid dysfunction and kidney. European Journal Endocrinology 2009; 160: 503-15.

4. Jordan SC, Johnston WH, Bergstein JM. Immune complex glomerulonephritis mediated by thyroid antigens. Arch Pathol Lab Med 1978; 102: 530-3.

5. Verger MF, Droz D, Vantelon J. Autoimmune thyroid disease associated glomerular nephropathy. 3 cases. Presse Med. 1983; 12(2): 83-6. 